\title{
A Front Tracking Model for Transient Solidification of Al-7wt.\% Si in a Bridgman Furnace
}

\author{
R. P. Mooney ${ }^{1} \cdot$ S. McFadden ${ }^{1,2} \cdot$ M. Rebow ${ }^{1} \cdot$ D. J. Browne ${ }^{3}$ \\ ${ }^{1}$ Dublin Institute of Technology, Bolton Street, Dublin 1, Ireland \\ ${ }^{2}$ Trinity College Dublin, Dublin 2, Ireland \\ ${ }^{3}$ University College Dublin, Belfield Campus, Dublin 4, Ireland \\ Corresponding Author: robin.mooney@mydit.ie
}

\begin{abstract}
The Bridgman furnace is widely used in industry and research. This paper outlines a working 1-dimensional model for tracking the columnar solidification front in a Bridgman furnace where the pulling velocity, and hence front position, change as a function of time. The front tracking model is applied to a fixed grid of control volumes using an explicit numerical finite difference scheme to solve the heat equation over a finite domain. The model is demonstrated by way of a notional scenario, namely, Bridgman furnace solidification of a 16-mm diameter rod of $\mathrm{Al}-$ $7 \mathrm{wt} . \% \mathrm{Si}$. The results show how the evolution of temperature distribution, thermal history, and front position are affected by a step change in pulling velocity.
\end{abstract}

Keywords Front tracking - Bridgman furnace - Velocity change $\cdot \mathrm{Al}-\mathrm{Si} \cdot$ Columnar growth

\section{Introduction}

The 'Bridgman Furnace' takes its name from the Nobel Prize winning physicist; Percy W. Bridgman, who developed a technique of lowering a pointed-bottom ampoule through a vertical tubular furnace to grow single crystal materials [1]. This method of solidification is widely used in industry to manufacture single crystal materials such as aero engine turbine blades [2]. In research, the Bridgman method has been used to examine dendritic growth of transparent materials in terrestrial [3] [4] and in microgravity [5] environments, and recently to observe peritectic growth [6][7]. The Bridgman technique has been used with X-ray videomicroscopy to observe real-time columnar dendritic solidification of alloys [8].

This paper describes a one-dimensional front tracking model for Bridgman furnace solidification at the mesoscale (at the scale of a crystal envelope). The model is demonstrated by way of a notional scenario; estimating the temperature profile, thermal history and columnar front position for Bridgman furnace solidification of an Al-7wt.\%Si rod. Transient solidification refers to the case where the front position changes as a function of time due to a step change in pulling velocity. Two cases are simulated and results are given with discussion.

\section{Materials and Methods}

\subsection{The Bridgman Furnace Front Tracking Model (BFFTM)}

The objective of the model is to simulate columnar growth in Bridgman solidification, using the front tracking model (FTM) of McFadden and Browne [9]. The 1D heat equation for a long cylindrical rod of uniform cross sectional area $A$, and perimeter $p$, moving at axial velocity $u$, and transferring heat laterally to the surroundings at its surface with heat transfer coefficient $h$, is given by equation (1) [10];

$\frac{\partial}{\partial t}\left(\rho C_{p} T\right)=\frac{\partial}{\partial x}\left(k \frac{\partial T}{\partial x}\right)-u \rho C_{p} \frac{\partial T}{\partial x}-\frac{h p}{A}\left(T-T_{\infty}\right)+E$

where, $T_{\infty}$ is the temperature of the surrounding source (or sink), and $E$ is the latent heat generated. The BFFTM algorithm uses an explicit finite difference control volume (CV) formulation to solve this equation at each $\mathrm{CV}$. It should be noted that the CVs are fixed in space - the sample is free to move through the fixed domain.

The Biot number, $B i$, relates the thermal resistance of diffusion in the rod, to the thermal resistance experienced at the surface of the rod, as given by equation (2); 


$$
B i=\frac{h L_{c}}{k}
$$

where, $L_{c}$ is the characteristic length of the rod, given by the ratio of the rod volume to its surface area through which $h$ acts. The model assumes a Biot number of less than 0.1 thereby vindicating an axial heat flow assumption [11].

In this 1-dimensional FTM, once nucleation has occurred, the columnar front position, $x_{c o l}$, is given by the distance from $x=0$ to a single marker $(x$ in Figure 1$)$.

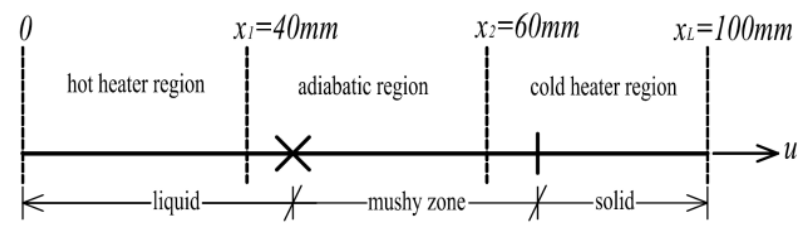

Figure 1: Bridgman Furnace front tracking model domain.

The temperature at this marker, $T_{x}$, is estimated by linear interpolation of the temperatures at the nearest $\mathrm{CV}$ centres. This temperature is checked against the equilibrium liquidus temperature, $T_{L}$, and the front can continue to grow as long as the marker is undercooled (i.e. $\Delta T>0$ ), according to equations (3) and (4), where $\left|v_{t i p}\right|$ is the columnar dendrite growth velocity. The front marker can move unidirectionally - that is, assuming a columnar front growth direction from the right hand side to the left hand side of Figure 1; if $u>\left|v_{t i p}\right|$ the marker will move from left to right, and vice versa for $u<\left|v_{t i p}\right|$.

$$
\begin{gathered}
\Delta T=T_{L}-T_{x} \\
\left|v_{t i p}\right|=C_{t} \Delta T^{n} \\
x_{c o l}^{1}=x_{c o l}^{0}+\left(u-v_{t i p}\right) \Delta t
\end{gathered}
$$

The front position is updated at every time step according to equation (5), where $\Delta t$ is the numerical scheme time step, and the superscripts 1 and 0 refer to the future and current temporal positions.

The latent heat term, $E$, is accounted for in two parts; latent heat released due to the advancement of the front, $E_{a}$, and latent heat released due to thickening of the mushy zone after the front has passed through, $E_{t}$, as given in equations (6)(7) and (8);

$$
\begin{gathered}
E=E_{a}+E_{t} \\
E_{a}=\frac{\rho L}{V_{C V}} g_{s} \frac{\partial V_{m}}{\partial t} \\
E_{t}=\frac{\rho L}{V_{C V}} V_{m} \frac{\partial g_{s}}{\partial t}
\end{gathered}
$$

where, $L$ is the latent heat of fusion, $V_{C V}$ is the volume of one $\mathrm{CV}$, and $g_{s}$ is the weight fraction of solid within the captured volume of mush, $V_{m}$, per $\mathrm{CV}$, as illustrated in Figure 2.

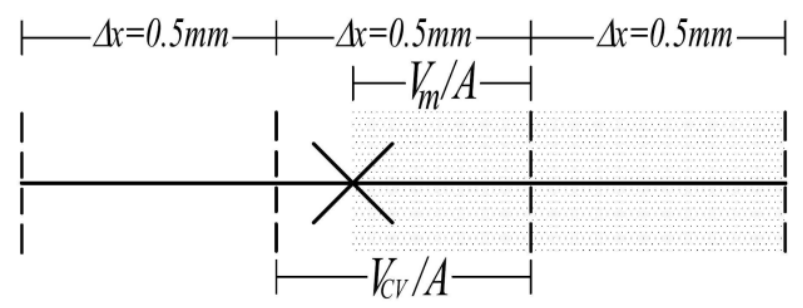

Figure 2: A control volume, $V_{C V}$, and captured volume of mush, $V_{m}$.

The solid fraction is estimated using a function of local temperature given by equation (9) derived from the Scheil equation [12].

$$
g_{s}=1-\left(\frac{T_{M}-T}{T_{M}-T_{L}}\right)^{\frac{1}{k_{p a r t}-1}}
$$

To solve equation (1) a Newton-Raphson iteration scheme is required to estimate solid fraction.

The model assumes that eutectic solidification of Al-Si occurs in equilibrium a eutectic front follows behind the columnar tracked front at the equilibrium eutectic temperature, $T_{E}$. The growth of eutectic solid is calculated using a conservative enthalpy method for isothermal freezing, as given by Voller [13].

\subsection{The Bridgman Furnace Setup}

The material modelled is a $16-\mathrm{mm}$ diameter rod of $\mathrm{Al}-7 \mathrm{wt} . \% \mathrm{Si}$, where second order polynomial functions of temperature are used to estimate the volumetric heat capacity, $\rho C_{p}$, and thermal conductivity, $k$. For full details of all thermophysical properties used see 
McFadden [14]. The key values for this alloy are shown in Table 1.

Table 1: $\quad$ Selected properties and dendrite growth data for Al-7wt.\%Si.

\begin{tabular}{|c|c|}
\hline Growth Constant, $C\left[\mathrm{~m} /{ }^{\circ} \mathrm{C}^{\mathrm{n}}\right]$ & $2.9 \times 10^{-6}$ \\
\hline Undercooling Index, $n$ [dimensionless] & 2.7 \\
\hline Liquidus Temperature, $T_{L}\left[{ }^{\circ} \mathrm{C}\right]$ & 618 \\
\hline Eutectic Temperature, $T_{E}\left[{ }^{\circ} \mathrm{C}\right]$ & 577 \\
\hline Melting Temperature of Pure $\mathrm{Al}, T_{M}\left[{ }^{\circ} \mathrm{C}\right]$ & 660.2 \\
\hline Alloy Partition Coefficient, $k_{\text {part }}$ & 0.13 \\
\hline Latent Heat, $L\left[\mathrm{~J} / \mathrm{m}^{3}\right]$ & $1064 \times 10^{6}$ \\
\hline
\end{tabular}

A notional Bridgman furnace problem is invented for simulation; with hot $\left(T_{H}\right)$ and cold $\left(T_{C}\right)$ heater temperatures set at $50^{\circ} \mathrm{C}$ above the equilibrium liquidus temperature $\left(T_{L}\right)$, and $50^{\circ} \mathrm{C}$ below the equilibrium eutectic temperature $\left(T_{E}\right)$, for the alloy, respectively. The adiabatic zone length is set at $20 \mathrm{~mm}$ at the centre of a $100 \mathrm{~mm}$ domain, divided into CVs of thickness $\Delta x=0.5 \mathrm{~mm}$, as shown in Figure 1 . The domain is governed by the boundary conditions given in equations (10) and (11);

$$
\begin{gathered}
T(x, t)=\left\{\begin{array}{lllll}
T_{H} & \text { at } & x=0 & \forall & t \\
T_{C} & \text { at } & x=x_{L} & \forall & t
\end{array}\right. \\
\frac{\partial T}{\partial x}=\left\{\begin{array}{lllll}
0 & \text { at } & x=0 & \forall & t \\
0 & \text { at } & x=x_{L} & \forall & t
\end{array}\right.
\end{gathered}
$$

where $x_{L}$ is the domain length. The sample is pulled through the furnace at a velocity, $u$.

\section{Results}

Two scenarios are simulated. In the first simulation (Figures 3 and 4); the initial temperature distribution is linear in the adiabatic zone, the sample pulling velocity is set to zero, and the temperature distribution in the domain is allowed to settle to a steady state. In the second simulation (Figures 5 and $6)$; the initial temperature distribution $\left(T_{\text {initial }}\right)$ is equal to the final temperature distribution from simulation $1\left(T_{\text {steady }}\right)$, and the pulling velocity undergoes a step change $(u=0 \rightarrow 0.5 \mathrm{~mm} / \mathrm{s})$ at $t=100 \mathrm{~s}$, followed by another step change $(u=0.5 \rightarrow 1.0 \mathrm{~mm} / \mathrm{s})$ at $t=500 \mathrm{~s}$.

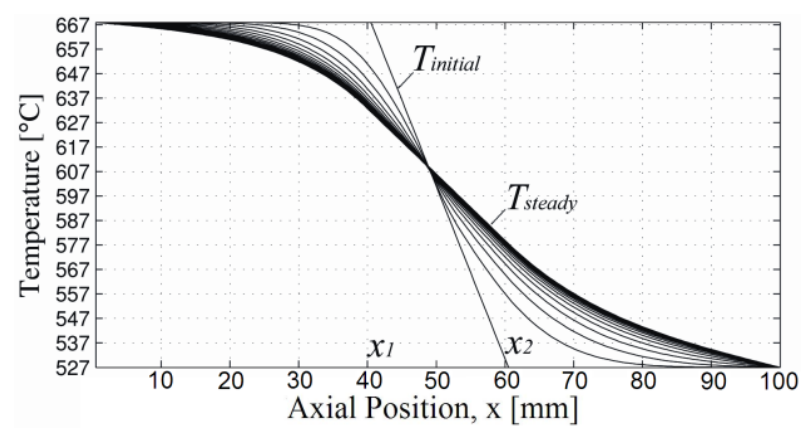

Figure 3: Simulation 1; Evolution of temperature distribution.

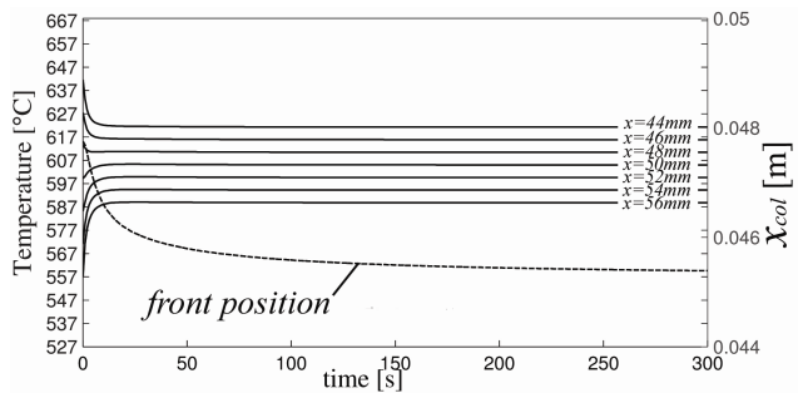

Figure 4: $\quad$ Simulation 1; Thermal history in adiabatic

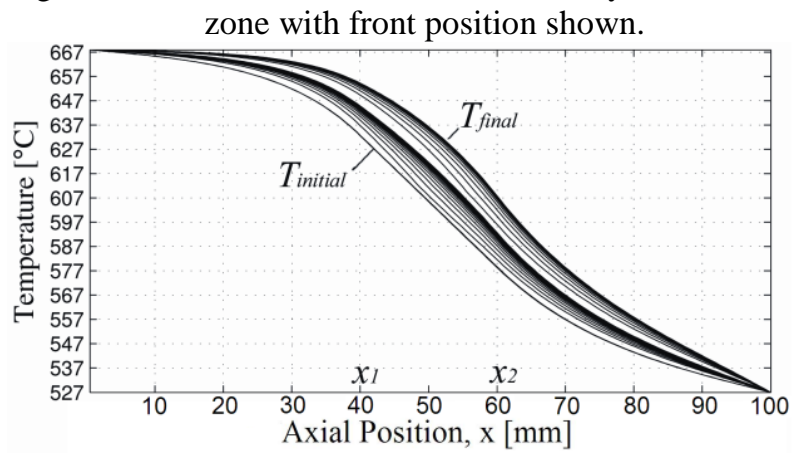

Figure 5: Simulation 2; Evolution of temperature distribution.

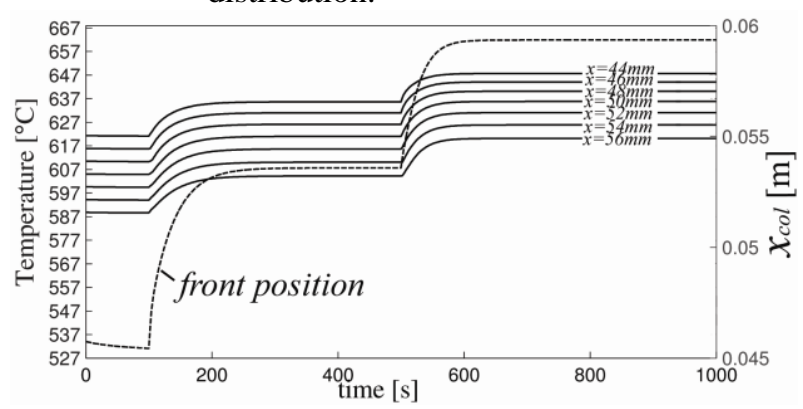

Figure 6: Simulation 2; Thermal history in adiabatic zone with front position shown.

\section{Discussion}

Figures 3 and 4 show how the temperature distribution and columnar front position settle to a steady state when the pulling velocity is set to zero. This result is of practical importance as it calculates the initial condition of a real Bridgman furnace experiment before 
the sample is moved. The final temperature distribution for simulation 1 is the starting temperature distribution for simulation 2 .

In Simulation 2 the effect of suddenly changing the pulling velocity is observed. The temperature profile undergoes a net increase in temperature due to new advection heat flux from the hot heater zone as a result of the change in velocity. The front position's reaction is typical of a first-order response to a step input. The front reaches a steady state (where the front velocity and pulling velocity match) within approximately 100secs for both step changes. The net effect of increasing the pulling velocity is to increase the dendrite tip undercooling and the volume of undercooled liquid ahead of the front. This scenario is useful in that these conditions could produce a columnar to equiaxed transition (CET) in a real experiment.

\section{Conclusion}

The BFFTM simulates columnar growth in a Bridgman furnace using the Scheil equation for solid fraction evolution. A double jump in pulling velocity is simulated and conditions to promote a CET are apparent.

Acknowledgements The authors would like to thank the European Space Agency for funding this research under the PRODEX programme. Thanks goes to all the GRADECET research partners, in particular Ulrike Hecht at Access e.v, Aachen, Germany.

\section{References}

[1] P. W. Bridgman, Proceedings of the American Academy of Arts and Sciences, vol. 60, p. 303, 1925.

[2] A. Kermanpur, N. Varahraam, E. Engilehei, P. Mohammadzadeh, and M. Davami, Materials Science and Technology, vol. 16, no. 5, pp. 579-586, 2000.

[3] K. A. Jackson and J. D. Hunt, Acta Metallurgica, vol. 13, no. 11, pp. 1212$1215,1965$.
[4] G. L. Ding, W. D. Huang, X. Huang, X. Lin, and Y. H. Zhou, Acta Materialia, vol. 44, no. 9, pp. 3705-3709, 1996.

[5] N. Bergeon et al., Advances in Space Research, vol. 36, no. 1, pp. 80-85, 2005.

[6] J. P. Mogeritsch, A. Ludwig, S. Eck, M. Grasser, and B. J. McKay, Scripta Materialia, vol. 60, no. 10, pp. 882885, 2009.

[7] J. Lapin and Z. Gabalcová, Intermetallics, vol. 19, no. 6, pp. 797 804, 2011.

[8] R. H. Mathiesen and L. Arnberg, Acta Materialia, vol. 53, no. 4, pp. 947-956, 2005.

[9] S. McFadden and D. J. Browne, Applied Mathematical Modelling, vol. 33, no. 3, pp. 1397-1416, 2009.

[10] H. S. Carslaw and J. C. Jaeger, Conduction of Heat in Solids, 2nd ed. London: Oxford University Press, 1959.

[11] F. P. Incropera, D. P. Dewitt, T. L. Bergman, and A. S. Lavine, Fundamentals of Heat and Mass Transfer, Sixth. John Wiley \& Sons, 2007.

[12] E. Scheil, Zeitschrift Fur Metallkunde, no. 34, pp. 70-72, 1942.

[13] V. R. Voller, Advances in Numerical heat Transfer, Volume 1. Taylor and Francis Ltd., 1997, pp. 341-380.

[14] S. McFadden, D. J. Browne, and C.-A. Gandin, Metallurgical and Materials Transactions A, vol. 40, no. 3, pp. 662672, 2009. 